\title{
Treinamento como mecanismo de prevenção de acidentes e incidentes: estudo de caso em uma construtora em Belo Horizonte, Minas Gerais
}

\author{
Training as an accident and incident prevention mechanism: case study in a constructor in Belo \\ Horizonte, Minas Gerais
}

La capacitación como mecanismo de prevención de accidentes e incidentes: estudio de caso en una constructor en Belo Horizonte, Minas Gerais

\author{
Alessandra Costa de Lima \\ ORCID: https://orcid.org/0000 0002-8707-4891 \\ Faculdade de Engenharia de Minas Gerais, Brasil \\ E-mail: clima.alessandra@gmail.com \\ Ludmila Julia Bittencourt de Souza Pereira de Oliveira \\ ORCID: https://orcid.org/0000-0002-0713-1842 \\ Faculdade de Engenharia de Minas Gerais, Brasil \\ E-mail: ludmilajulia@yahoo.com.br \\ Reinam Pereira de Oliveira \\ ORCID: https://orcid.org/000-0003-3555-9659 \\ Faculdade de Engenharia de Minas Gerais, Brasil \\ E-mail: reinam.oliveira@civilmaster.com.br \\ Talita Rodrigues de Oliveira Martins \\ ORCID: https://orcid.org/000-0002-3850-5042 \\ Faculdade de Engenharia de Minas Gerais, Brasil \\ E-mail: talita22r@yahoo.com.br
}

\begin{abstract}
Resumo
O presente estudo aborda a Saúde e Segurança do Trabalho (SST), na Construção Civil (CC) onde o foco foi dado na importância do treinamento dos profissionais deste setor como uma das mais importantes ferramentas para redução dos números de acidentes e incidentes no universo comum aos canteiros de obras. O objetivo do estudo foi identificar os riscos presentes em um canteiro de obras localizado na região noroeste de Belo Horizonte, Minas Gerais e considerar as bases normativas para elaboração de um programa de treinamento na Gestão de Segurança do Trabalho com foco na prevenção de acidentes e incidentes no canteiro de obras. Como resultados verificou-se que existem riscos significativos de acidentes e incidentes de trabalho no canteiro de obras observado e por meio de treinamentos, o supervisor e trabalhadores, são instruídos também sobre o uso adequado dos Equipamentos de Proteção de Segurança, que se dividem em equipamentos de proteção individual e equipamentos de proteção coletiva relativos ao risco de cada atividade e possibilita verificar diariamente a regularidade desses equipamentos.
\end{abstract}

Palavras-chave: Construção civil; Saúde e segurança do trabalho; Acidentes; Treinamento.

\begin{abstract}
This study addresses Occupational Health and Safety (OSH), in Civil Construction (CC) where the focus was on the importance of training professionals in this sector as one of the most important tools for reducing the number of accidents and incidents in the common universe to construction sites. The objective of the study was to identify the risks present in a construction site located in the northwest region of Belo Horizonte, Minas Gerais and to consider the normative bases for the elaboration of a training program in Workplace Safety Management with a focus on the prevention of accidents and incidents at the construction site. As a result, it was found that there are significant risks of accidents and work incidents at the construction site observed and through training, the supervisor and workers are also instructed on the proper use of Safety Protection Equipment, which is divided into equipment individual protection and collective protection equipment related to the risk of each activity and makes it possible to check the regularity of this equipment on a daily basis.
\end{abstract}

Keywords: Civil construction; Health and safety; Accidents; Training.

\section{Resumen}

Este estudio aborda la Seguridad y Salud Ocupacional (SST), en la Construcción Civil (CC) donde el foco estuvo en la importancia de la formación de los profesionales de este sector como una de las herramientas más importantes para reducir el número de accidentes e incidentes en el universo común para sitios de construcción. El objetivo del estudio fue identificar los riesgos presentes en un sitio de construcción ubicado en la región noroeste de Belo Horizonte, Minas 
Gerais y considerar las bases normativas para la elaboración de un programa de capacitación en Gestión de Seguridad Laboral enfocado en la prevención de accidentes y incidentes en el sitio de construcción. Como resultado, se encontró que existen riesgos importantes de accidentes e incidentes laborales en el sitio de construcción observado y mediante la capacitación, el supervisor y los trabajadores también son instruidos sobre el uso adecuado de los Equipos de Protección de Seguridad, los cuales se dividen en equipos de protección individual y equipos de protección colectiva relacionados con el riesgo de cada actividad y permite comprobar diariamente la regularidad de estos equipos.

Palabras clave: Construcción civil; Salud y seguridad; Accidentes; Capacitación.

\section{Introdução}

O presente estudo aborda a temática da SST, na Engenharia de Produção sendo aplicada aos mais diversos setores produtivos, dentre eles, os canteiros de obras. Especificamente, foca-se na importância do treinamento dos profissionais como uma das mais importantes ferramentas para redução dos números de acidentes e incidentes no universo comum às Construtoras dos mais diferentes portes. A Norma Regulamentadora, (NR) 35 de 2012 se complementa com as normas técnicas oficiais estabelecidas pelos Órgãos competentes e, na ausência ou omissão dessas, com as normas internacionais aplicáveis. Considerase também, o que preceitua a NR 18 - Condições e Meio Ambiente de Trabalho na Indústria da Construção atualizada em 2020.

Não são raros os casos relatados formalmente e formalmente de acidentes de trabalho em canteiros da Construção Civil, CC que envolvem lesões permanentes e muitas vezes o óbito do trabalhador. O setor tem merecido atenção por parte de especialistas, gestores públicos e privados, além dos profissionais da SST e daqueles que trabalham na CC como postula Campos (2011). Baseando nas NR’s 18 e 35, tem-se a disposição das condições de meio ambiente de trabalho na indústria da construção e devem-se alinhar os aspectos da Segurança no Trabalho contextualizado na realidade da indústria da CC (Araújo, 2012).

Segundo Nunes (2016), o treinamento necessita elucidar os procedimentos e medidas que possam garantir a execução das atividades com segurança. É preciso trabalhar conceitos básicos, demolição, atividades de carpintaria, estrutura metálica, andaimes, telhados e coberturas, locais confinados, instalações elétricas, proteção contra incêndio, sinalização de segurança, treinamento, entre vários outros assuntos. Diante da abordagem inicial sobre o tema, considera-se a seguinte questão para o estudo: Como podem ser elaborados os treinamentos para se desenvolver a capacidade de executar as atividades de trabalho com segurança evitando acidentes e incidentes no canteiro de obras. O objetivo geral é apresentar uma proposta de treinamento fundamentado nas NR's 18 e 35 com foco na prevenção de acidentes e incidentes diante dos riscos identificados em um canteiro de obras situado em Belo Horizonte, Minas Gerais.

\section{Desenvolvimento}

\subsection{Saúde e segurança do trabalhador na construção civil}

No âmbito da SST direcionado à CC, Pereira (2008) e Melo (2012) retratam que os acidentes no campo do labor vêm sendo paulatinamente associados a patrões de negligência que despontam condições de trabalho fragilizadas e inseguras, sendo considerado também, os empregados com postura displicente que acabam por cometer ações que geram insegurança e risco. No tocante às Normas e Regulamentos, Vilela (2013) e Palasio (2018) citam que a SST no setor da CC baseia-se em NR's expostas na Portaria 3214/78 do Ministério do Trabalho e Emprego (MTE). Dentre essas normas, cita-se a NR-18 estabelecendo liames administrativos, de planejamento e de organização de modo a conduzir a implementação de ações e política de controle e sistemas sob a ótica preventiva e segurança nos processos, considerando também as condições e o meio ambiente laboral na esfera da Construção, além de também definir a elaboração do Programa de Condições e Meio Ambiente de Trabalho na Indústria da Construção (PCMAT) (Vilela, 2013).

Melo (2012) assinala que elaborar e implantar medidas de pertencimento ao PCMAT é uma questão obrigatória em estabelecimentos com 20 ou mais colaboradores. As empresas que contam com um número inferior a 20 trabalhadores têm a 
obrigatoriedade de elaborar somente o Programa de Prevenção de Riscos Ambientais (PPRA), sendo obrigatório para totalidade das empresas deste segmento de modo a gerenciar melhor o risco de acidentes de trabalho que permeiam as atividades da CC como se vê adiante.

\subsection{Acidentes nos canteiros de obras da construção civil}

Araújo (2005) e Antônio (2009) retrata que a história remonta que a área de CC apresenta expressivos índices de acidente de trabalho no decorrer da execução de uma obra. Nesse contexto, a Gerência de Segurança do Trabalho, GST, desponta como essencial fator na redução e até eliminação das ocorrências de acidentes. $\mathrm{O}$ autor reforça que muitos insistem na ideia de que em grandes obras, os riscos, que já são

Para Almeida (2010) e Thame (2010), os riscos envolvidos na CC devem cumprir a NR-18 que trata das condições de Meio Ambiente de Trabalho no setor da Construção. E sustenta que quando foi concebida, a norma tinha como foco as construções de edificações. Atualmente, na Comissão Permanente Nacional (CPN), existe essa compreensão e, nesse sentido, está sendo elaborando itens de normas específicas para o segmento de grandes obras.

Freitas (2008) descreve que fazer o controle da SST no canteiro de uma grande obra não é fácil. Considera-se a presença de inúmeros desafios de ordem técnica e gerencial e não somente referentes ao controle de SST. O planejamento da obra é crucial para a melhoria da segurança e diminuição dos riscos de acidentes. Conhecer as características locais onde a obra será realizada é fundamental como: tipo de solo e terreno, condições meteorológicas, incidência de raios, mão de obra disponível, logística para transporte de equipamentos e pessoas, infraestrutura

Rousselet (2006); Oliveira (2010); Lima (2013); Reis e Batista (2009); Vilela (2013) mencionaram que as construtoras têm revelado certa preocupação com a excelência em habitabilidade, conciliando as necessidades dos clientes com aspectos de inovação construtiva, gerando produtos sob medida para os usuários, preocupando-se com a eficiência energética e com a reutilização dos recursos naturais renováveis.

\subsection{Principais normas em segurança e saúde na construção civil}

Com base no que dizem Lopes (2013), o Brasil oferece diversos instrumentos jurídicos que abordam e tratam da SST, o primeiro deles, citado pelo autor foi o Decreto-Lei $n^{\circ} 5.452$, em 1943, que promulgou a Consolidação das Leis do Trabalho (CLT). Esta última, por meio de seu capítulo V - Da Segurança e Medicina do Trabalho, com alteração da Lei $n^{\circ} 6.514$, de 22 de dezembro de 1977, estabelece tratativas para os problemas da saúde do trabalhador. Em seguida, a portaria $\mathrm{n}^{\circ} 3.214$, de 1978 , aprovou, conforme art. 200 da CLT, as NR's relativas à Segurança e Medicina do Trabalho.

A NR-18 - Condições e Meio Ambiente de Trabalho no setor da Construção em seu item 18.1.1 estabelece os limites e parâmetros sob o alcance administrativo, das atividades relacionadas ao planejamento e à organização, que buscam elaborar e implementar ações de controle e sistemas que sejam preventivos de segurança nos processos, nas condições e no meio ambiente de trabalho na CC (Cardella, 2009).

Considera-se que mesmo diante do que estabelece a NR-18, reconhecendo que ainda há muito a ser feito sob os aspectos da SST, contribui muito para uma significativa redução dos índices de acidentes do trabalho na CC. O PCMAT no segmento da Construção Civil constitui-se um instrumento da máxima importância na prevenção de acidentes em canteiros de obras, propiciando detalhamento das proteções coletivas em consonância com o cronograma físico da obra (Almeida, 2010).

Sobre a NR 35, responde por trazer definição das diretrizes de segurança mínimas que precisam ser obedecidas em trabalhos executados em grandes alturas. Tratam-se, não só do momento de realização da atividade em si, mas abarca o planejamento e organização desta. Sendo assim, essa norma parte da premissa de que o trabalho em grandes alturas, a atividade realizada a mais de 2 metros do nível inferior do solo e nas quais existam o risco de queda (SERRA, 2010). 
O empregador também tem a responsabilidade não permitir o início de qualquer atividade até o cumprimento da norma seja cumprida, exigindo obediência à NR 35 ainda que aos prestadores de serviço, e interrompendo as atividades diante imprevistos que levem às condições de risco, até a sua até sua resolução. Deve o empregador, disponibilizar treinamento e informações aos trabalhadores acerca de como agir, de modo preventivo, e a respeito dos riscos e fiscalizar a implementação das medidas estabelecidas pela NR 35, produzindo relatórios com informações sobre riscos, medidas adotadas e atividades do projeto realizando a documentação e arquivamento desses documentos (Oliveira, 2020).

\subsection{Treinamentos de prevenção de acidentes e incidentes}

Segundo Vilela (2013), o treinamento refere-se ao processo de auxiliar o colaborador a adquirir eficiência no seu trabalho presente ou futuro, por meio de hábitos adequados, pensamentos e ações, habilidades, conhecimentos e atitudes. Já Dezan (2017) menciona que um programa de treinamento de prevenção de acidentes nos canteiros de obras pode resultar em diversos benefícios ao colaborador e por conseguinte, as organizações. O autor ainda destaca que ao colaborador internamente, tem-se a melhoria da eficiência dos serviços; o aumento da eficácia nos resultados; o estímulo à criatividade e inovação na SST alinhados à cultura da organização.

Barbosa e Ramos (2012) apontam que o treinamento em SST reforçam a melhoria da qualidade de vida no trabalho; o aumento da qualidade e produtividade nas tarefas desempenhadas; garantia de um melhor atendimento ao cliente. Já no âmbito externo, o autor cita que o treinamento proporciona ao colaborador maior competitividade organizacional; acesso e propostas de outras organizações e melhoria da imagem profissional.

\section{Metodologia}

Quanto aos procedimentos técnicos e a coleta de dados, pode-se dizer que a abordagem utilizada foi qualitativa, visto que esta técnica procurou analisar os riscos de acidentes de trabalho vistos em um canteiro de obras em Belo Horizonte, Minas Gerais, buscando a qualidade para exposição de dados e informações. Além disso, foram realizadas visitas em dias aleatórios no local no mês de dezembro de 2020, para observação não participante, em que se buscou registrar as situações de risco de acidentes e incidentes no canteiro de obras em questão.

Segundo Vergara (2011) o estudo aqui delineado, tem-se que se trata de um tipo de pesquisa básica, tipo de estudo que busca produzir conhecimentos novos para o aperfeiçoamento e contribuição da ciência sem aplicação prática prevista. No que diz respeito às técnicas, as mesmas relacionam-se à coleta de dados, pertinente ao conjunto de práticas da pesquisa Gil (2017) trata-se de um estudo de campo procurando pelo aprofundamento das questões propostas com maior preocupação com a distribuição das características da população segundo determinadas variáveis. A abordagem foi qualitativa, com a reunião de informações acerca do campo de interesse por meio de pesquisa bibliográfica, já a documentação direta refere-se ao levantamento de dados realizados no próprio local em que os fatos se dão por meio de pesquisa de campo (Lakatos; Marconi; Marconi, 2011).

Foi realizada em uma área que se objetiva aprofundar no conhecimento acumulado e sistematizado, considerando a etapa da busca por mais informações sobre o assunto dos acidentes e incidentes no canteiro de obras e como preveni-los. Segundo Gil (2017), não se pode acreditar que somente os indivíduos são as únicas fontes de informações válidas na pesquisa acadêmica. Considera-se todo material documental tais como registros em papel, arquivos públicos e privados, publicações internas, dados estatísticos, etc., sendo importantes fontes de informações para o estudo, obtidas mediante documentação indireta. Como limitações a pesquisa aqui proposta, pode-se dizer que a mesma se refere somente ao canteiro de obras investigado, não podendo ser ampliados os resultados obtidos para outros canteiros. 


\section{Apresentação e Análise dos Resultados}

\subsection{Descrição da empresa e da obra}

A empresa analisada foi denominada $\mathrm{ABC}$, para fins de sigilo e para preservar a sua identidade, a pedido da mesma. A ABC possui um significativo quadro de funcionários, 154, dentre eles, 110 ficam lotados em canteiro de obras. Assim sendo, foi escolhido um dos canteiros das obras da empresa analisada, conforme Figura 1, localizado na Região Nordeste no Bairro Castelo, na cidade de Belo Horizonte, MG.

Figura 1 - Empreendimento da construtora analisada.

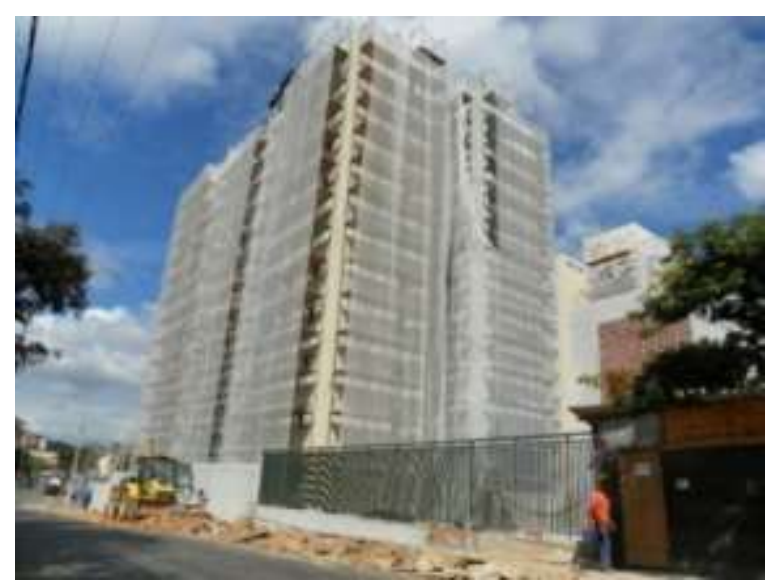

Fonte: Autores (2021).

\subsection{Sobre o canteiro de obras observado e a SST}

\subsubsection{O mapa de risco}

De início, pode-se dizer que a $\mathrm{ABC}$ apresentou um modelo de mapa de riscos ambientais que possibilitou identificar alguns dos riscos de acidentes e incidentes de trabalho. O mapa (Figura. 2) foi elaborado e confeccionado pela Comissão Interna de Prevenção de Acidentes (CIPA), porém a data era de 2011/2012, o que não garantia a atualização das informações nele contidas.

Figura 2 - Mapa de risco disposto no canteiro de obras da construtora analisada.

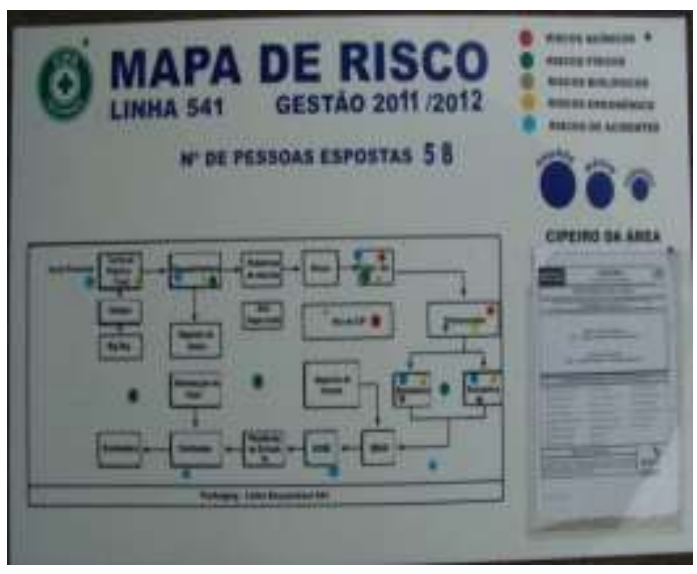

Fonte: Autores (2021).

Embora cada empresa possa adotar símbolos (cores e formatos) próprios para a elaboração dos mapas, importando que eles sejam mantidos nos diferentes espaços ou empreendimentos como apontam Guimarães e Reis (2017). Em modelos mais 
completos, as construtoras devem incluir a quantidade de pessoas expostas a cada risco e uma tabela com ações preventivas para neutralizá-los, o que não foi constatado.

\subsubsection{Riscos de acidentes identificados}

Um dos principais riscos de acidentes e incidentes que pôde ser observado no canteiro de obras na $\mathrm{ABC}$ foi a possibilidade da queda de funcionários, materiais construção e ferramentas conforme foi abordado por Silva (2018) e demonstrado na Figura 3:

Figura 3 - Situação de risco do trabalho em altura no canteiro de obras visitado.

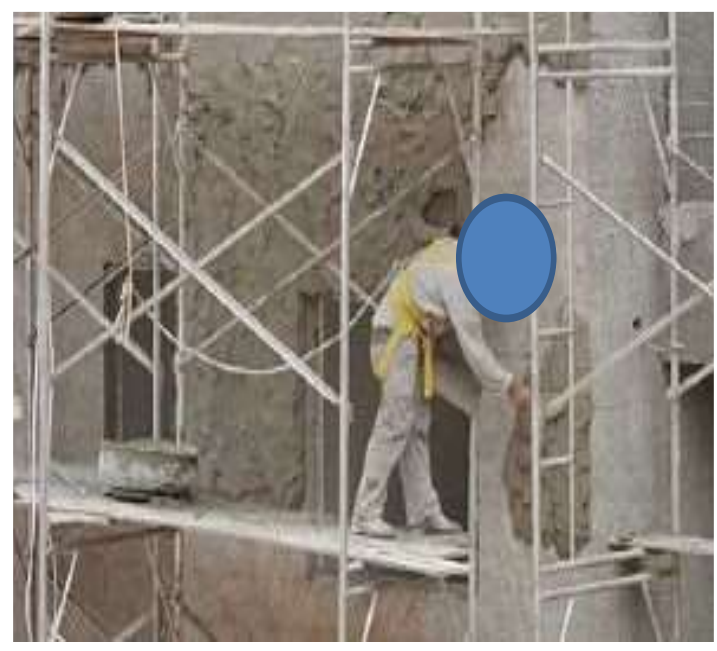

Fonte: Autores (2021)

A utilização de dispositivos adequados para proteção contra quedas de pessoas, materiais e pequenos equipamentos também não foi constatado com regularidade, o risco de quedas é iminente em trabalhos em altura como visto no canteiro de obras observado e como destacou Almeida (2010). Na Figura 4, o profissional estava devidamente assegurado pelo uso do capacete e cintos e cabos de aço que visavam sua proteção.

Figura 4 - Situação do trabalho em altura no canteiro de obras visitado com profissional bem equipado.

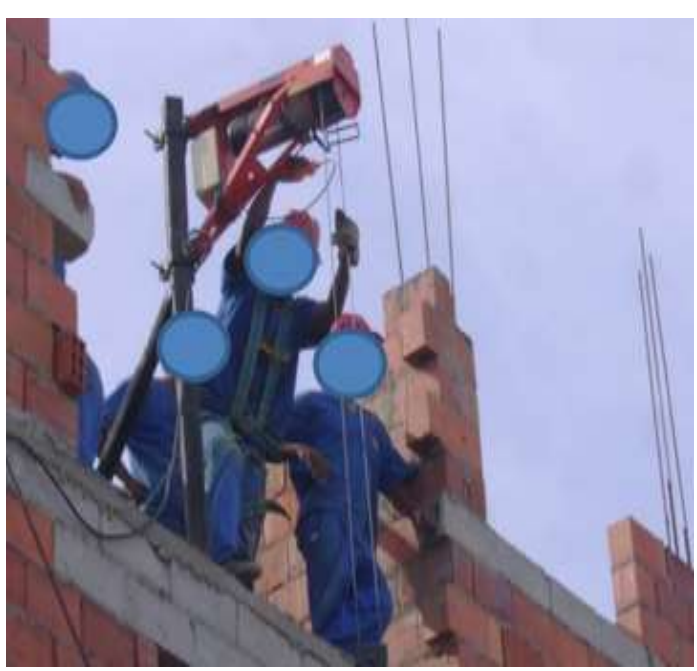

Fonte: Autores (2021). 
Importante destacar também a questão relacionada à ordem, organização e limpeza com relação direta a causa de acidentes citada por Oliveira (2020). Isto porque, as condições inadequadas de coleta, armazenagem, segregação, destinação de resíduos de obra como visto na Figura 5, e de insumos gerais que, se não for corretamente dimensionado se apresenta como risco físico (quedas, cortes) e químico (contato com produtos tóxicos), resultando em risco de acidentes e incidentes.

Figura 5 - Disposição inadequada de materiais de construção e resíduos.

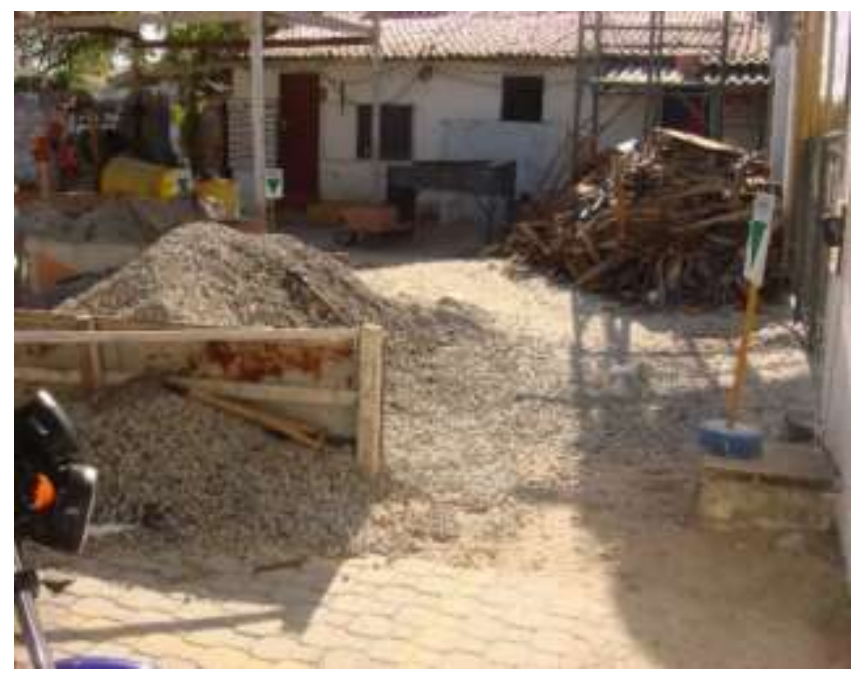

Fonte: Autores (2021).

Já o setor de estoque estava bem organizado e com um layout que reduzia o risco de quedas dos materiais, e que estes se tornassem obstrução na passagem dos trabalhadores. Em determinadas situações, foi possível identificar o risco específico de acidentes com a inadequada destinação dos resíduos da construção como mostrado na Figura 6, deste modo o cenário se tornava propício a queda e consequentes lesões aos trabalhadores.

Figura 6 - Local com a disposição do entulho da obra sem sinalização e proteção contra acidentes e incidentes.

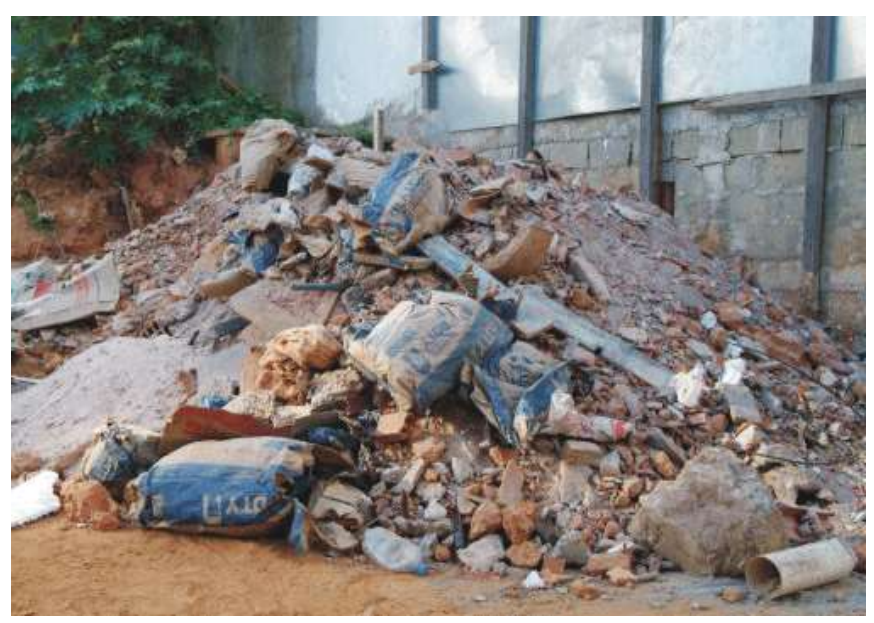

Fonte: Autores (2021)

A Construtora ABC seguiu alguns dos procedimentos de Permissão para Trabalhos Especiais (PTE) visto no estudo de Cardella (2009), atendendo ao plano de treinamento. Porém, foi constatado o descumprimento da NR-33 - Trabalhos em Espaço Confinado visto na Figura 7 com a não utilização das práticas adequadas para deslocamento do profissional no espaço com equipamento de segurança, usando somente capacete, porém sem máscara e ferramentas definidas (iluminação). 
Figura 7 - Exemplo de trabalho realizado no canteiro de obras em condições parcialmente adequadas.

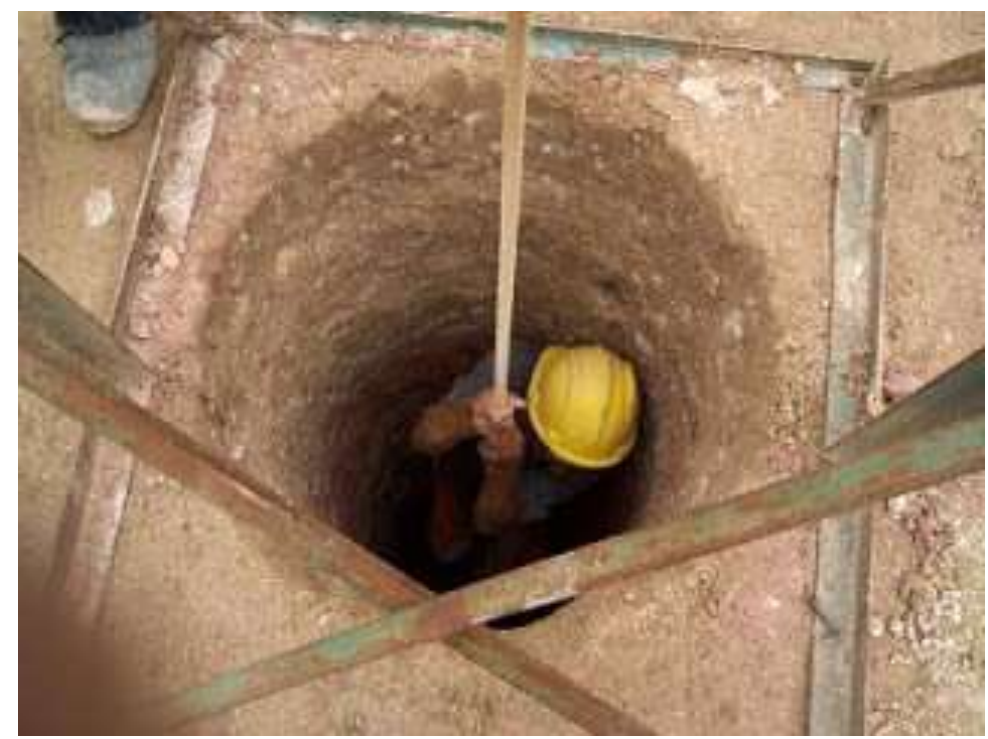

Fonte: Autores (2021).

No que se refere à sinalização, essa se mostrou adequada, apresentando-se com a correta etiquetagem e bloqueio de equipamentos e com o uso de dispositivos para segregação e circulação segura de pessoas assim como também aborda Palasio (2018). Pôde-se constatar o uso de placas, sinalização apropriada, etiquetas de bloqueio e tipos de bloqueio. A Figura 8 mostra a sinalização do perigo ao abrir o painel elétrico.

Figura 8 - Sinalização em uma das áreas do canteiro de obras.

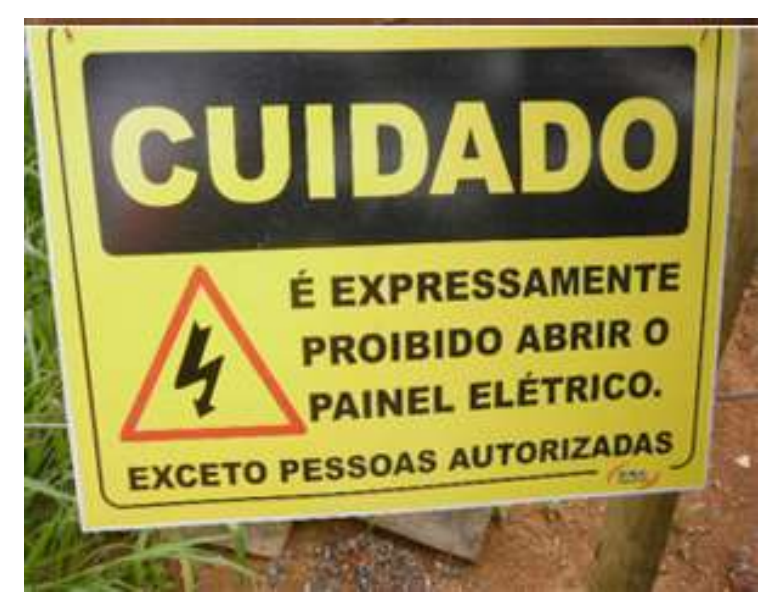

Fonte: Autores (2021).

No que diz respeito aos equipamentos móveis e motorizados, Pereira (2008) reforça que o uso indevido de equipamentos, a improvisação e questões de manutenção inapropriada aumenta consideravelmente o riso de acidentes. As condições de sinalização que envolve a movimentação também devem ser adequadas no que tange à sinalização viária tal como mostra a Figura 9. 
Figura 9 - Sinalização de alerta no trânsito e descrição do risco no canteiro de obras.

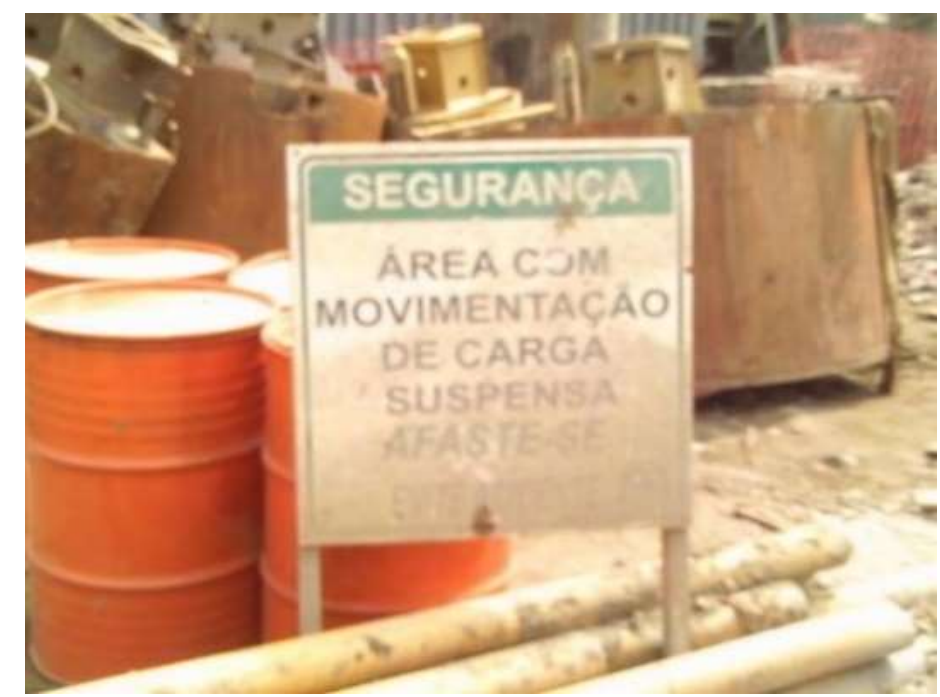

Fonte: Autores (2021)

Importa destacar a questão do uso de EPI em condições apropriadas, como postula Dezan (2017) deve-se alertar quanto à falta, o uso correto e as condições de conservação e reposição de equipamentos de proteção pessoal de todos os tipos (mãos, pés, cabeça, visão, respiratório etc.). A Figura 10 mostra o estoque de EPIS no canteiro de obras analisado.

Figura 10 - Estoque de EPIs oferecido pela Constru - ABC aos funcionários no canteiro de obras.

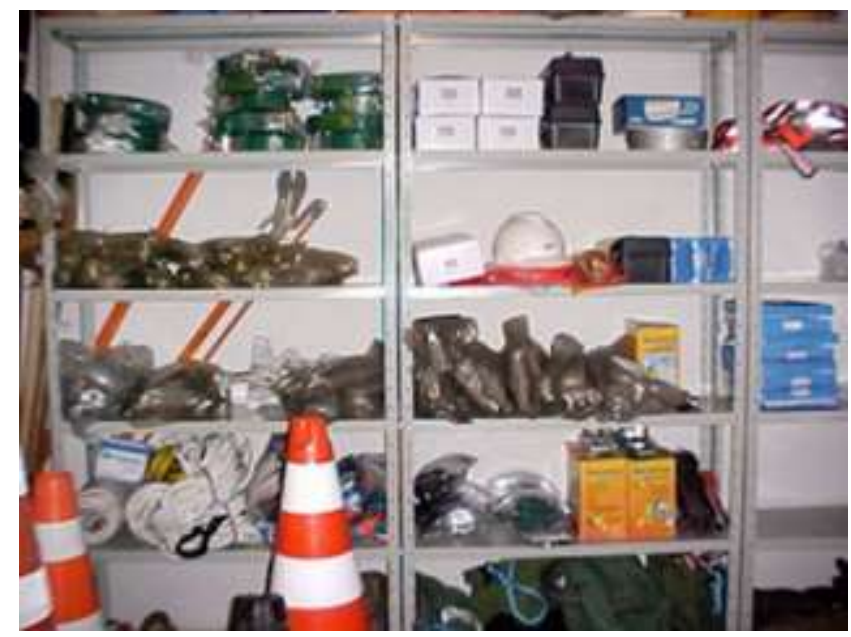

Fonte: Autores (2021).

A proteção de máquinas/equipamentos e ferramentas se apresentou de forma correta, sem a observação, em tempo, de improvisação de proteção de máquinas. Mas em alguns casos, o uso inapropriado de ferramentas manuais e elétricas pode ser constatado como, assim com revela a Figura 11, em que a bancada de serra circular estava com a fiação exposta e o trabalhador não usava nenhum EPI. 
Figura 11 - Trabalho executado por um funcionário sem uso de nenhum EPI.

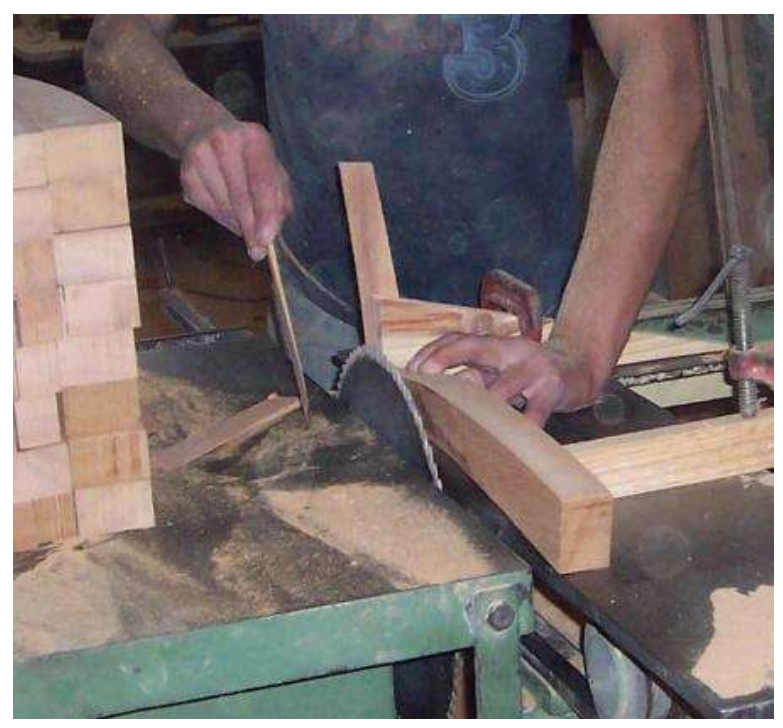

Fonte: Autores (2021)

Nas situações de fundação e demolição, não foram verificadas faltas de procedimentos de segurança para realização do trabalho seguro, constatou-se condições físicas dos trabalhos como: escoramento apropriado, estoque de materiais em bordas de escavações, existência de escada e rampa para acesso seguro. Sobre as instalações da infraestrutura incluindo as oficinas, sanitários, vestiários, área de alimentação todas essas áreas possuíam acessibilidade segura no que diz respeito ao transporte de pessoas.

Conforme observado, a saúde e a integridade física do trabalhador, devido à incidência elevada de acidentes de trabalho só pode ser garantida, com cuidados específicos em cada atividade e espaço do canteiro de obras como destaca Thame (2010). A falta de conhecimento dos trabalhadores é uma dificuldade que pode ser vencida por ações da CIPA e eventos como SIPAT. Em termos gerais, identificou-se cuidados relacionados a evitar os riscos de acidentes e danos à saúde dos trabalhadores no canteiro de obras analisado e também situações que precisam ser mais bem policiadas e monitoradas.

\subsection{Proposta para o treinamento de prevenção contra acidentes no canteiro de obras}

Incialmente, levantou-se os riscos de acidentes e incidentes mais frequentes que poderiam acontecer durante os diversos serviços da construção do empreendimento, assim como os EPI que devem ser utilizados. Instalação dos EPC será discutido em "proteção coletiva” como defendem Vilela (2013) e Silva (2018). Ressalta-se que antes de ministrar o treinamento, os conhecimentos dos riscos básicos de cada função, devem servir como base para preparar material específico (slides, impressos) para cada uma delas, com os devidos riscos e medidas preventivas contra acidentes adotadas e propostas pela empresa.

\subsubsection{Etapas do treinamento}

Deve-se apresentar o Treinamento de prevenção contra acidentes e incidentes baseados nos parâmetros da NR 18 e NR35 como uma norma bastante exigente. Sobre quem pode ministrar treinamento de prevenção de acidentes, tem-se que a norma não especifica quem pode, mas, presume-se que na parte de Segurança do Trabalho deve ministrar o treinamento alguém quem tenham formação em Segurança do Trabalho. Qualquer um funcionário que tenha formação no segmento poderá ministrar. O Quadro 1 resumo das etapas constituintes da proposta de treinamento para as construtoras. 
Quadro 1 - Etapas de treinamento proposto baseados na NR 18 e NR35.

\begin{tabular}{|c|c|c|}
\hline Etapa & Descrição & Sugestão \\
\hline $\begin{array}{l}\text { 1- História da } \\
\text { Empresa }\end{array}$ & $\begin{array}{l}\text { Para apresentar a história da empresa, indica-se elaborar um } \\
\text { resumo contando como a empresa nasceu, quem foram os } \\
\text { fundadores, o que fabrica, o que constrói, em quais estados atua, } \\
\text { filiais, etc }\end{array}$ & $\begin{array}{l}\text { Linha de tempo da empresa; fotos com empreendimentos } \\
\text { marcantes; evolução da gestão da empresa; primeiros } \\
\text { registros de acidentes e incidentes e primeiras ações de } \\
\text { melhoria no âmbito da SST }\end{array}$ \\
\hline $\begin{array}{l}2 \text { - Importância da } \\
\text { Segurança } \\
\text { Trabalho }\end{array}$ & $\begin{array}{l}\text { Deve-se considerar a importância da Segurança do Trabalho, } \\
\text { demonstrando o que a empresa e o funcionário devem assumir } \\
\text { como deveres e enxergar como direitos no primeiro contato } \\
\text { funcionário-construtora. Descrever a Política de segurança da } \\
\text { empresa, caso não se tenha, orienta-se analisar a possibilidade } \\
\text { de criar uma }\end{array}$ & $\begin{array}{l}\text { deve-se mostrar e trabalhar uma frase de efeito sobre o } \\
\text { tema: A ABC acredita que trabalhar com segurança é } \\
\text { obrigação de todos. Deve-se demonstrar que os } \\
\text { funcionários da empresa são o bem maior, por isso, não } \\
\text { se pode secundarizar as normas de segurança e de } \\
\text { garantir um ambiente de trabalho mais seguro e } \\
\text { harmonioso para todos. Sugere-se: mostrar e conceituar } \\
\text { os símbolos; falar das NR relacionadas à SST, da CIPA } \\
\text { e PCMAT e da história da SST. }\end{array}$ \\
\hline $\begin{array}{l}3 \text { - Objetivo do } \\
\text { Treinamento }\end{array}$ & $\begin{array}{l}\text { Deve-se deixar claro o objetivo do treinamento é importante } \\
\text { para trazer à discussão a importância que cada funcionário tem } \\
\text { no treinamento e na empresa. }\end{array}$ & $\begin{array}{l}\text { Abordar quantos funcionários a construtora tem; o } \\
\text { número de acidentes na Construção Civil; as } \\
\text { possibilidades de ocorrência desses acidentes na } \\
\text { empresa; a importância e o papel de cada funcionário } \\
\text { para prevenir acidentes e demonstrar a gravidade dos } \\
\text { acidentes e quais são os incidentes comuns aos canteiros } \\
\text { de obras }\end{array}$ \\
\hline $\begin{array}{l}4 \text { - Explicar o que é } \\
\text { segurança do } \\
\text { Trabalho }\end{array}$ & $\begin{array}{l}\text { Mostra-se o que significa a ST e o crescimento acentuado da } \\
\text { construção civil, verificado nos últimos anos em todo o país, } \\
\text { acompanhado pelo aumento do número de acidentes de trabalho } \\
\text { e de mortes de operários, principalmente por soterramento, } \\
\text { queda ou choque elétrico }\end{array}$ & $\begin{array}{l}\text { Mostrar o número total de acidentes X acidentes na } \\
\text { construção civil, o número de mortes e aposentadoria por } \\
\text { invalidez, exemplos positivos de ações de ST no canteiro } \\
\text { de obras e estimular o senso de responsabilidade de cada } \\
\text { funcionário na ST da ABC. }\end{array}$ \\
\hline $\begin{array}{l}5 \quad \text { - Informações } \\
\text { sobre as condições e } \\
\text { meio ambiente de } \\
\text { trabalho }\end{array}$ & $\begin{array}{l}\text { Esse tópico pode ser feito mostrando informações gerais sobre } \\
\text { os riscos no ambiente. Deve-se deixar claro que o acidente faz } \\
\text { parte da produção, que é obra do acaso. Não, o acidente é } \\
\text { principalmente obra do descaso, da falta da cultura de } \\
\text { prevenção - disse, observando ainda o aumento da tensão no } \\
\text { ambiente do trabalho. Especificamente no canteiro de obra, } \\
\text { deve-se ter em mente todas as possíveis situações que podem } \\
\text { incorrer em acidentes }\end{array}$ & $\begin{array}{l}\text { Mostrar a situações de risco de acidentes e incidentes; } \\
\text { apresentar fotos de acidentes e incidentes no canteiro de } \\
\text { obras e mostrar e explicar um mapa de risco de um } \\
\text { canteiro. }\end{array}$ \\
\hline $\begin{array}{l}6 \text { - Riscos inerentes à } \\
\text { função exercida: }\end{array}$ & $\begin{array}{l}\text { Nesta etapa, é importante mostrar os riscos inerentes a cada } \\
\text { função de forma clara e com linguagem de fácil entendimento, } \\
\text { evitando termos técnicos e palavras complicadas. Ressalta-se } \\
\text { que se deve ser bem específico nesse tópico do treinamento }\end{array}$ & $\begin{array}{l}\text { Sugere-se elaborar um quadro com cada função e } \\
\text { detalhar os possíveis riscos de acidentes de cada um }\end{array}$ \\
\hline $\begin{array}{l}7-\quad \text { EPI's } \\
\text { Equipamentos } \\
\text { Proteção Individual }\end{array}$ & $\begin{array}{l}\text { Orienta-se que seja detalhado cada um dos EPIs utilizados na } \\
\text { Construção Civil, a proteção que eles oferecem e dispor de } \\
\text { amostras sobre a mesa e mostre como usá-los na prática. Isto } \\
\text { porque, a prática é fundamental para ensinar e quebrar mitos. } \\
\text { Deve-se mostrar a importância do uso de EPI's e com exemplos } \\
\text { claros, mostre que o trabalhador pode perder muito em caso de } \\
\text { acidente, se não estiver usando os EPI's }\end{array}$ & $\begin{array}{l}\text { Sugere-se-levar os EPIs utilizados; demonstrar a forma } \\
\text { correta do seu uso; mostrar como cada um evita } \\
\text { acidentes; trabalhar em cima de um quadro descritivo de } \\
\text { acidentes e incidentes-formar de prevenção }\end{array}$ \\
\hline $\begin{array}{l}8 \quad-\quad \text { EPC }- \\
\text { (Equipamentos de } \\
\text { Proteção Coletiva) } \\
\text { que existem no local }\end{array}$ & $\begin{array}{l}\text { A orientação desta etapa é mostrar como o EPC funciona, quais } \\
\text { são os utilizados no canteiro de obras, a importância deles, e } \\
\text { orientar sobre como conservar os que já estão instalados na } \\
\text { empresa }\end{array}$ & $\begin{array}{l}\text { Levar alguns dos EPCs e mostrar as fotos com sua } \\
\text { utilização. }\end{array}$ \\
\hline 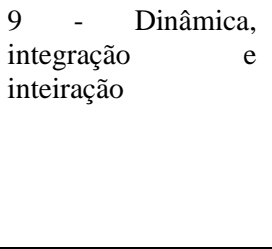 & Depois de realizar exames médicos e ginástica laboral. & $\begin{array}{l}\text { Sugere-se dinâmicas em que os trabalhadores participem } \\
\text { de palestras e debates sobre prevenção de acidentes no } \\
\text { trabalho, doenças sexualmente transmissíveis, } \\
\text { transtornos psicológicos, alimentação saudável, inserção } \\
\text { de mulheres e de pessoas com deficiência nos canteiros } \\
\text { de obras e cuidados com o meio ambiente no lar e na } \\
\text { construção. }\end{array}$ \\
\hline 10 - Agradecimentos & $\begin{array}{l}\text { Oferecer um certificado de participação, tirar foto para ser posto } \\
\text { em um mural etc. Por fim, deve-se agradecer a atenção e diga } \\
\text { que a empresa conta com a colaboração de todos. Além disso, é } \\
\text { importante deixar um espaço para perguntas e observações dos } \\
\text { participantes, reforçar a importância de colocar em prática o que } \\
\text { foi ministrado e aprendido por eles no treinamento e que a } \\
\text { segurança de cada um depende de cada um }\end{array}$ & $\begin{array}{l}\text { Sugere-se entregar um Kit com brindes que lembrem o } \\
\text { treinamento, como bótons de "eu participei" ou } \\
\text { "prevenir acidentes é o meu papel"; canetas, capacetes } \\
\text { personalizados com o tema e etc }\end{array}$ \\
\hline
\end{tabular}

Fonte: Autores (2021). 


\section{Considerações Finais}

Este estudo buscou demonstrar como pode ser elaborado e ministrado um treinamento de prevenção de acidentes em uma construtora, com relação ao dia a dia de um canteiro de obras. A obra citada, de uma empresa de grande porte, também conta com um termo de responsabilidade assinado pelo funcionário admitido para assegurar e trazer caso ocorra futuramente um acidente o fato de que ocorreu o treinamento e ciência de todos os protocolos, regras e procedimentos a serem seguidos na obra, bem como prazos de validade de certificados e treinamentos dentro do estipulado pelos Órgãos de Fiscalização competentes.

A partir das observações e estudo realizado, pôde-se compreender que um fator de fundamental importância atrelado diretamente à prevenção de acidentes refere-se à antecipação dos riscos. Este princípio fundamenta-se na promoção de reuniões preparatórias a respeito dos temas abordados, dando voz e espaço aos funcionários que atuam diretamente com os riscos inerentes ao trabalho em altura, os quais são conhecedores dos perigos e riscos no ambiente de trabalho. Ao receberem treinamentos, o supervisor e trabalhadores, são instruídos também sobre o uso adequado dos Equipamentos de Proteção de Segurança, que se dividem em equipamentos de proteção individual e equipamentos de proteção coletiva relativos ao risco de cada atividade e verificar diariamente a regularidade desses equipamentos.

Conclui-se que o treinamento para a prevenção de acidentes e incidentes no canteiro de obras deve conceber o espaço existente para se trabalhar a melhoria das condições de trabalho. É preciso fomentar a conscientização e um treinamento de trabalhadores do canteiro de obras visando a adoção de práticas seguras dentro dos canteiros de obra. A linguagem deve ser de fácil compreensão e os pontos principais enfocados no treinamento devem se fundamentar na realização de um diagnóstico dos principais problemas que sistematicamente ocorrem nas obras.

\section{Referências}

Antônio, S. (2009). Plano de Cargas para Gruas Instaladas em Canteiro de Obras. São Paulo.

Araújo, L. M. (2005) Trabalho e saúde-doença nas indústrias da construção civil de João Pessoa (PB). Dissertação (Mestrado em Ciências Sociais), Universidade Federal da Paraíba, João Pessoa.

Araújo, G. M. (2012). Normas Regulamentadoras Comentadas. Rio de Janeiro. $8^{\text {a }}$. ed

Barbosa, L. O.; Ramos, W. (2012) Importância da prevenção de acidentes no setor de construção civil: um estudo de caso em Uberlândia, Minas Gerais, Brasil. Revista Conhecimento Online - Ano 4 - Vol. 2, setembro.

BRASIL. MINISTÉRIO DO TRABALHO. (2000) NR 35 - Atividades e Operações Insalubres. Rio de Janeiro

BRASIL. MINISTÉRIO DO TRABALHO. (2016) NR 18 - Condições e Meio Ambiente de Trabalho na Indústria da Construção Civil. Rio de Janeiro, 2016.

Campos, J. L.D. (2011). O Ministério Público e o meio ambiente do trabalho responsabilidade civil e criminal do empregador e prepostos. FUNDACENTRO. São Paulo.

Cardella, B. (2009) Segurança no Trabalho e Prevenção de Acidentes: uma Abordagem Holística: Segurança Integrada à Missão Organizacional com Produtividade e Qualidade. 1. ED. São Paulo: Atlas.

Dezan, G. (2017) Guia para gestão de segurança nos canteiros de obra: orientação para prevenção dos acidentes e para o cumprimento das normas de SST / Coordenação Roberto Sérgio Oliveira Ferreira. — Brasília, DF: CBIC.

GIL, A. C. (2017) Como elaborar projetos de pesquisa. 4. ed. São Paulo: Atlas.

Guimarães, G. M., Reis, M. B. (2017) Segurança do Trabalho na Construção Civil: Dados Estatístico de Acidentes de Trabalho e a Prática da Segurança nos Canteiros de Obras. Araraquara, p 25 -29.

Lakatos, E. M; Marconi, M. A. (2011) Fundamentos de metodologia científica. 6. Ed. São Paulo: Atlas.

Lima, F. L. (2013). Número de acidentes de trabalho na construção civil preocupa especialistas. http://www12.senado.gov.br/noticias/materias/2013/03/11/numero-de-acidentes-de- trabalho-na-construcao-civil-preocupa-especialistas.

Lopes, R. (2013). Construção civil: número de acidentes de trabalho diminui mesmo com aumento de obras. 2013. http://www.sindusconpr.com.br/principal/home/?sistema=conteudos\%7Cconteudo\&id_conteudo=1393.

Melo, M. B. F. V. (2012) Influência da cultura organizacional no Sistema de Gestão da Segurança e Saúde no Trabalho em empresas construtoras. Tese de doutorado, UFSC. Florianópolis. 
Research, Society and Development, v. 10, n. 6, e19610615672, 2021

(CC BY 4.0) | ISSN 2525-3409 | DOI: http://dx.doi.org/10.33448/rsd-v10i6.15672

Nunes, F. de O. (2016). Segurança e Saúde no Trabalho Esquematizada. $3^{\mathrm{a}}$. ed. Ed. Forense.

Oliveira, T. J. C. (2010) Um Estudo Sobre a Insalubridade Térmica e Produtividade de Trabalhadores em um Protótipo de Central de Concreto e Argamassa na Cidade de Juazeiro do Norte (CE). (Dissertação de Mestrado em Engenharia de Produção).

Oliveira, S. G. (2020) Número de acidentes de trabalho na construção civil preocupa especialistas. http://www12.senado.gov.br/noticias/materias/2020/03/11/numero-de-acidentes-de- trabalho-na-construcao-civil-preocupa-especialistas.

Palasio, C. (2018). Segurança em andaimes. Artigo. São Paulo.

Pereira, J. G. (2008). NR-10 - Segurança e Instalações e Serviços em Eletricidade. Apostila. Belo Horizonte.

Reis, J. T.; Batista, J.C. (2009). A empreitada na indústria da construção civil, o acidente de trabalho e a responsabilidade civil. Rio de Janeiro: Editora LTr.

Rousselet, E. S. (2006) A Segurança na Obra Manual - Manual Técnico de Segurança do Trabalho em Edificações Prediais. Rio de Janeiro, SICOM/RJ/SENAI - DN/CBIS.

Serra, S.M.B. (2010) Segurança e saúde no trabalho em canteiros de obras. In: ARAÚJO, N.M.C. (Org.). Construção Civil: uma abordagem macro da produção ao uso. João Pessoa: SINDUSCON / IFPB. Cap.5, p.105-124.

Silva, A. L. C.A (2018) Segurança do Trabalho como uma Ferramenta para a Melhoria da Qualidade. <http://repositorio.ufsm.br/bitstream/handle/1/8206/SILVA\%2c\%20ANDRE\%20LUIS\%20CABRAL.pdf?sequence=1\&isAllowed=y >. A

Thame, A. C. de M. (2010) Leis que nos Defendem. IQUAL - Instituto de Qualificação e Editora Ltda. São Paulo.

Vergara, S. C. (2011). Projetos e relatórios de pesquisa em administração, 5. Ed. São Paulo: Editora Atlas.

Vilela, R. A. G. (2013) Desafios da vigilância e da prevenção de acidentes do trabalho. São Paulo: LTr. 